\title{
Management of corrosive esophageal burns in 149 cases
}

Jing-Hai Zhou, MD, Yao-Guang Jiang, MD, Ru-Wen Wang, MD, Yi-Dan Lin, MD, Tai-Qian Gong, MD, Yun-Ping Zhao, MD, Zheng Ma, MD, and Qun-You Tan, MD

\author{
Extra material is available \\ online. $\widetilde{\vartheta}$
}

Objectives: We sought to present our experience in the management of esophageal burns.

Methods: From April 1976 through October 2003, 149 patients with corrosive esophageal burns were included in this study. Treatment modalities consisted of modified intraluminal stenting in 28 , colon interposition in 71 , gastric transposition in 25 , repair of cervical stricture with platysma myocutaneous flap in 17 , and miscellaneous operations in 12 patients. Eleven of these patients underwent the above procedures twice at our institute. The remaining 7 patients were treated with conservative therapy.

Results: Twenty-three patients recovered from intraluminal stenting, and 5 experienced stricture after stent removal. One of the 5 patients with failed stents responded to bougienage, and the remaining 4 patients required esophageal reconstruction later. Of the 71 colon interpositions, 5 patients died postoperatively, and complications consisted of proximal anastomotic fistula in 17, anastomotic stenosis in 6, and abdominal incision dehiscence in 2 patients. Postoperative complications in the 25 patients with gastric transpositions comprised anastomotic stricture in 2 patients and empyema in 1 patient. There was a cervical leak in 1 of the 17 patients undergoing the repair of cervical esophageal or anastomotic stricture with a platysma myocutaneous flap. One of the patients in the group undergoing 12 miscellaneous procedures died 8 months after surgical intervention. All the survivors currently eat regular diets.

Conclusions: Intraluminal stenting can prevent the formation of caustic esophageal stricture. The location of the cicatricial esophagus dictates whether to perform concomitant esophagectomy during esophageal reconstruction. Platysma myocutaneous flap repair is an excellent method for the treatment of severe cervical esophageal or anastomotic stricture.

$\mathrm{E}$ sophageal burns comprise various groups of lesions in terms of burn location, admitting time after ingestion, and complications. Therefore management of these injuries has been a challenge to thoracic surgeons, otolaryngologists, and gastroenterologists. Although it has been well accepted that the early phase of management of the stable patient is prevention of stricture formation, it remains a controversy as to which is the optimal treatment modality among neutralization of caustics, corticosteroids, antibiotics, esophageal dilation, stenting, and surgical intervention. ${ }^{1,2}$ Colon, ${ }^{3,4}$ stomach,${ }^{5}$ jejunum, ${ }^{6}$ and myocutaneous flap ${ }^{7}$ can be used to reconstruct the esophagus, but there is still controversy, irrespective of whether the cicatricial esophagus is resected during the procedure. ${ }^{8}$ Finally, the treatment of undilatable cervical esophageal or anastomotic stenosis has not been well defined. ${ }^{9}$

We present our experience of 149 cases of corrosive esophageal burns in the past 27 years. Specifically, we report a technique for the prevention of stenosis devel- 


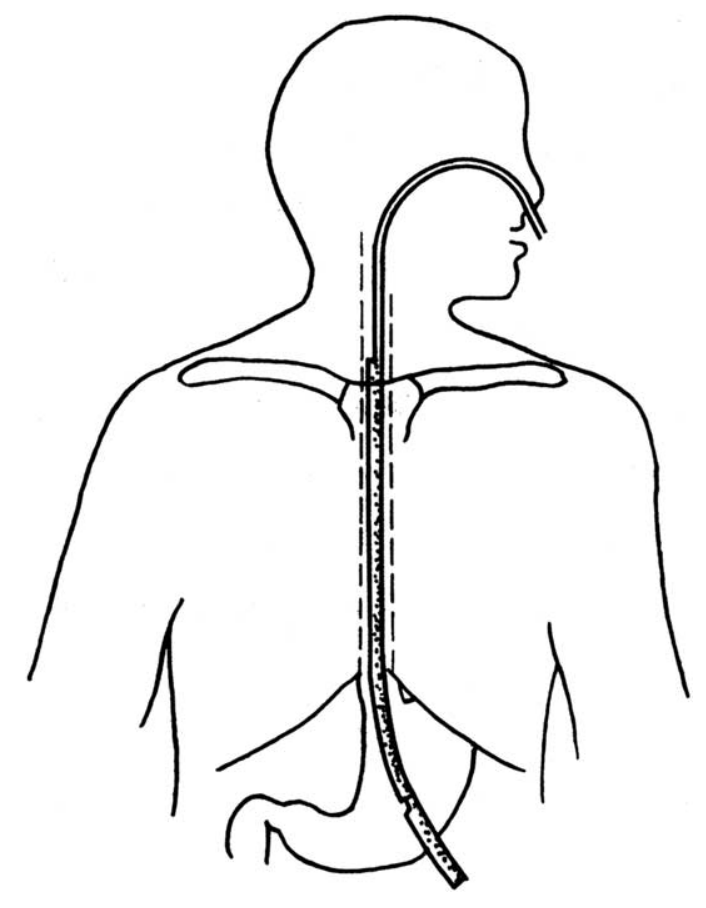

Figure 1. Correct position of the modified intraluminal stent. Catheter that suspended the upper end of the stent is fastened through the nostril, and its lower end, used as a feeding gastrostomy, is fixed on the abdominal wall.

opment with modified intraluminal esophageal stenting and repair of severe cervical esophageal or anastomotic strictures resistant to dilation with a platysma myocutaneous flap. ${ }^{10}$

\section{Patients and Methods \\ Patients}

From April 1976 through October 2003, 149 patients with caustic esophageal burns were included in this study. There were 97 male and 52 female patients, ranging in age from 1 to 72 years (average age, 25 years). Forty-four (29.5\%) patients were between the ages of 1 and 14 years. The most common caustic agent was alkali in $121(81.2 \%)$ patients, followed by acids in $20(13.4 \%)$ patients. Four patients swallowed pesticides. Several drops of molten iron splashed into the mouth and esophagus of 2 furnace operators. The other 2 patients ingested unclear liquid. Among the 149 patients with caustic agent ingestion, 112 ingestions were accidental, and 37 were in an attempt to commit suicide. The quantity of corrosives swallowed was from 1 to $150 \mathrm{~mL}$.

The period from the time of caustic ingestion to hospital admission ranged from 1 hour to 120 months. Thirty-five patients were admitted less than 3 weeks after ingestion of the corrosive agent. The remaining 114 patients were admitted more than 3 weeks after swallowing caustic agents. In the former group, all but one patient with esophageal perforation underwent esophagoscopy, and the degree of injuries was evaluated. There were 30 patients with second- or third-degree injuries. The remaining 5 patients with first-degree esophageal burns were treated conservatively and had a normal intake of food after being followed up for 3 months. The other 2 patients, who swallowed corrosive agents in a suicide attempt and were given a diagnosis of third-degree esophageal injury by means of esophagoscopy, declined to undergo operations and died of acute peritonitis and massive hemorrhage on the fourth and sixth days after the injury, respectively. The remaining 28 patients underwent intraluminal stenting. As for the 114 patients admitted more than 3 weeks after their injuries, esophageal barium and esophagoscopy studies showed that the esophageal stricture was too severe to undergo dilation or the duration was too long for patients to keep on dilating in 92 cases. These patients underwent esophageal reconstruction more than 6 months after their injuries. They maintained nutrition through feeding gastrostomy or esophageal dilations before esophageal replacement. The other treatment modalities included repair of cervical esophageal or anastomotic strictures with platysma myocutaneous flaps and performing miscellaneous operations.

\section{Modified Intraluminal Stenting}

The procedure was modified on the basis of the technique introduced by Reyes and Hill. ${ }^{11}$ The stent was constructed from a medical silicone rubber tube in the range of 40 to $60 \mathrm{~cm}$ in length, 1.0 to $1.2 \mathrm{~cm}$ in inside diameter, and 1.4 to $1.6 \mathrm{~cm}$ in outside diameter. A $12 \mathrm{~F}$ catheter was affixed to the proximal end of the stent with a transfixion ligature to prevent distal migration. The distal end of the stent was tailored into the shape of a duck's beak and was transfixed with 10-0 thread to pull the stent (Figure E1).

A midline laparotomy was carried out after achievement of general anesthesia. The abdominal esophagus, serosal surface of the stomach, and pylorus were evaluated at celiotomy, especially in patients swallowing acidic agents. A gastrotomy at the anterior gastric wall was made. A nasogastric tube was inserted preoperatively. The proximal end of the nasogastric tube was pulled out of the mouth, and its distal end was brought out of the stomach through the gastrotomy. If the nasogastric tube was not inserted successfully because of esophageal stricture, a dilator was placed during endoscopy. Two strings of 10-0 filament were tied to the distal end of the nasogastric tube or the dilator in the abdomen. An assistant pulled up the nasogastric tube or dilator to bring the knot of the 10-0 filament out of the oral cavity while the other end of the filament was kept in the abdomen. The nasogastric tube or dilator was removed. One string of the filament out of the mouth was connected with the thread that tied to the distal end of the esophageal stent. The other string of the filament was attached to another nasogastric tube, which was sheathed in the stent earlier to guide the stent and prevent it from diverting. The stent was inserted in an antegrade fashion (Figure E2). The nasogastric tube was extracted through the mouth. Then the upper end of the stent was positioned to $2 \mathrm{~cm}$ below the esophageal orifice by direct laryngoscopy. A side core, the diameter of which is larger than half of the stent's circumference, was cut at the intragastric wall of the stent. Finally, the catheter that suspended the upper end of the stent was fastened through the nostril. Its lower end, used as a feeding gastrostomy, was fixed on the abdominal wall (Figure 1). 

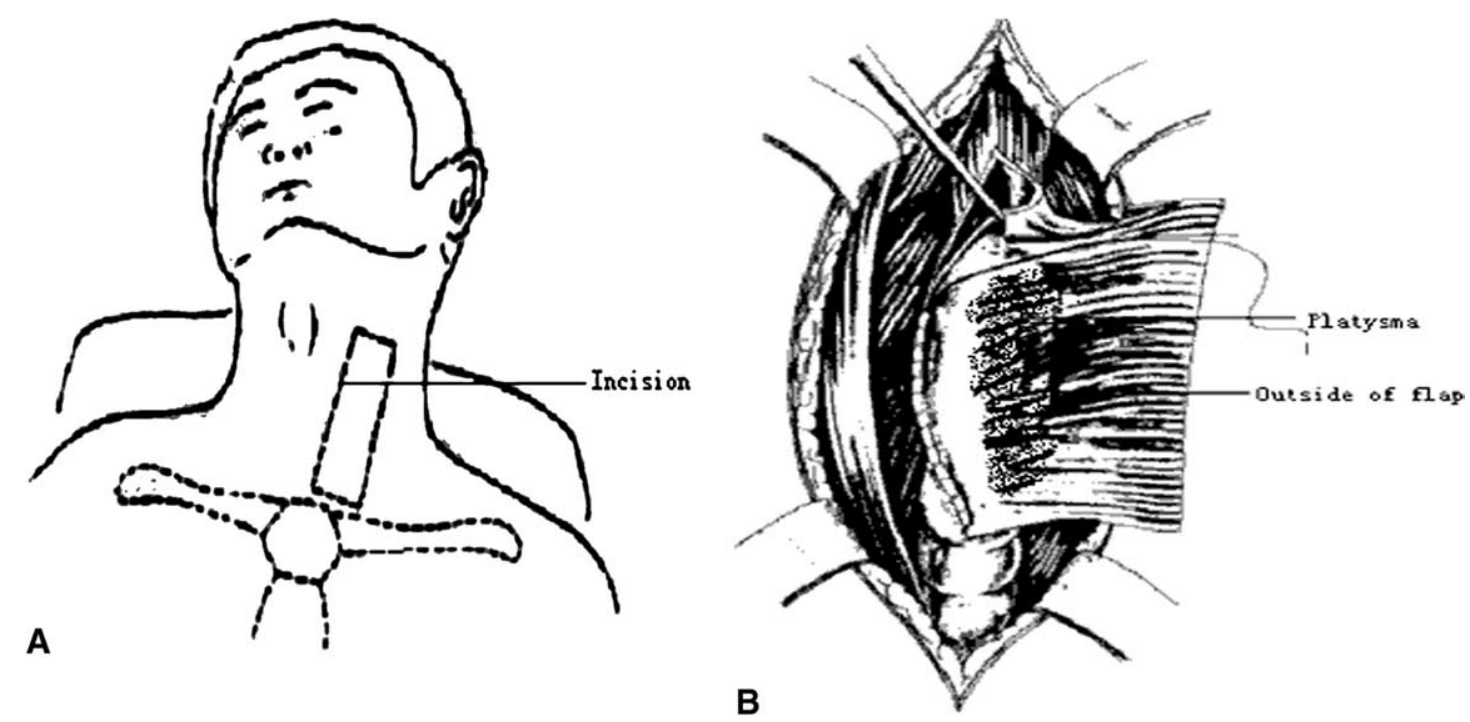

Figure 2. A, Incision along the anterior border of the left sternocleidomastoid. B, Completeness of cervical esophageal stricture repair with a platysma myocutaneous flap. The skin flap is rolled up with the skin side facing the esophageal lumen.

\section{Colon Interposition}

Colon interposition was performed when the patients required esophageal reconstruction and the esophageal stricture was located proximal to the carina. These patients underwent esophageal reconstruction in a range from 6 to 58 months (mean, 12.2 months) after their injuries. The surgical procedures were made according to the techniques introduced by Thomas and colleagues. ${ }^{4}$

\section{Gastric Transposition}

Esophagectomy and gastric transposition were performed by thoracotomy when the esophageal stricture was located distal to the carina. These patients underwent esophageal reconstruction in a range from 6 to 34 months (mean, 12.2 months) after their injuries. After the burned esophagus was removed, the stomach was mobilized through division of the left gastric, left gastroepiploic, and short gastric vessels. Then the cardia was resected and closed with a transfixion suture. The gastric fundus was anastomosed with thoracic or cervical esophagus.

\section{Platysma Myocutaneous Flap Repair}

Severe cervical esophageal or anastomotic strictures that would not respond to dilation were repaired with platysma myocutaneous flaps. This technique was introduced by Professor Wang and Professor Jiang of our group. ${ }^{10}$ The patients were in a supine position, and the head deviated to the right side. An incision was made along the anterior border of the left sternocleidomastoid muscle (Figure 2, A). An 18F endotracheal tube was inserted through the oral cavity preoperatively to define the proximal end of the esophageal stricture. Then the stricture was split longitudinally, extending to $1 \mathrm{~cm}$ each beyond the proximal and distal edges. A left platysma myocutaneous flap was used to widen its lumen. The designed area of the platysma myocutaneous flap, generally 4 to 5 $\mathrm{cm}$ in width and 7 to $8 \mathrm{~cm}$ in length, depended on the scope of the defect. The anterior, superior, and inferior incisions of the myocutaneous flap were extended through the platysma, but the posterior incision of the flap was carried through the skin only down to the platysma muscle (Figure E3). The skin flap was rolled up with the skin facing the lumen and sutured to the incised margin of the stricture (Figure E4 and Figure 2, B). Penrose drains were placed overlying and underlying the flap.

\section{Miscellaneous Procedures}

Miscellaneous operations were performed in the remaining 12 patients. A plasty procedure for anastomotic stricture was performed in 2 patients who had undergone esophageal reconstruction. Pyloroplasty was performed in 8 patients, and the other 2 patients underwent gastrojejunostomy.

\section{Results}

\section{Modified Intraluminal Stenting}

Modified intraluminal esophageal stenting was performed in 28 patients who were admitted less than 3 weeks after their injuries. The stent was kept in place for 4 to 6 months because most of the scar was stabilized at that time. Twentythree patients had a full diet without dysphagia, and 5 patients had strictures after removal of the stent. Among the latter group, 1 patient responded to dilation. Four patients were unresponsive to repeat dilation and required esophageal replacement. The time interval from withdrawal of the stent to esophageal replacement ranged from 9 to 44 months (average, 18 months). Colon interposition was performed in 2 patients, and gastric transposition was performed in the other 2 patients. All 4 patients have had a normal diet after undergoing esophageal reconstruction. 


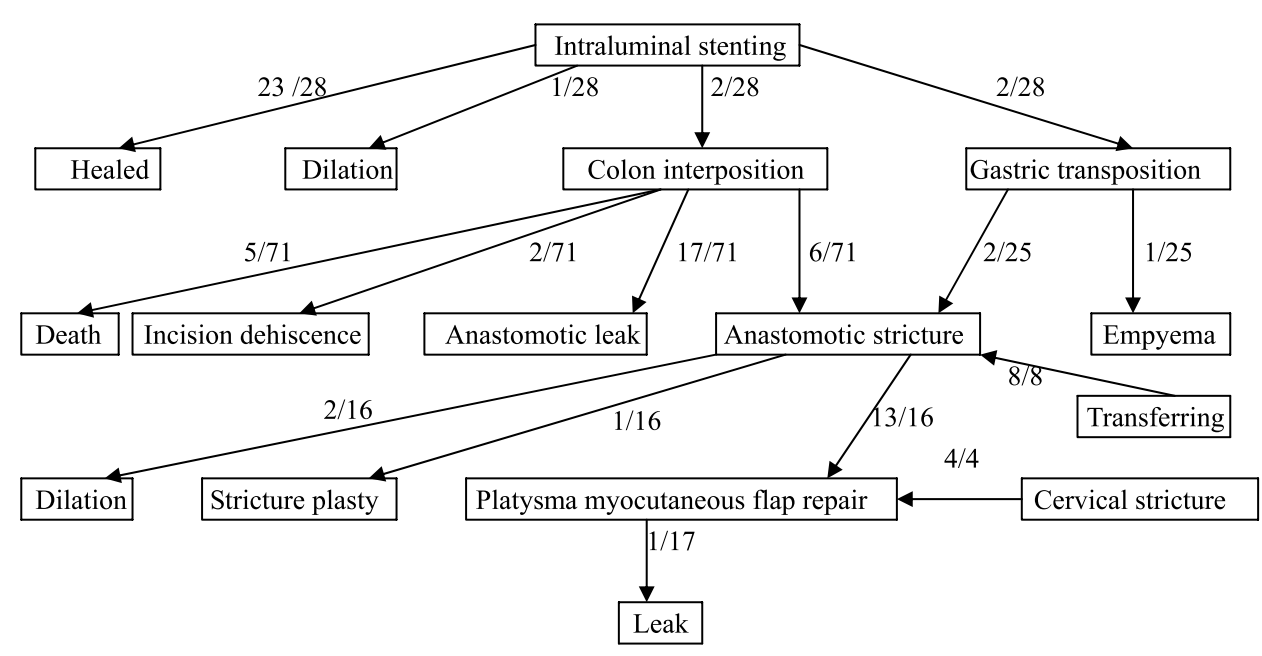

Figure 3. Flow chart of summary of treatment modalities but miscellaneous procedures in the patients with caustic esophageal burns.

\section{Colon Interposition}

Colon interpositions were made in 71 patients, including 2 with failed intraluminal stents. All the transplants were placed below the sternum. The left colon was used in 68 patients, and the right colon was used in 3 patients. Colon interposition with terminal ileum was performed in 1 patient of the latter group. All the blood supply depended on the middle colonic artery. The upper end of the transplant was anastomosed with the cervical esophagus in 57 patients and with the hypopharynx in 14 patients. Two patients underwent total gastrectomy and colojejunostomy because of stomach injuries. Five (7.0\%) postoperative deaths occurred between days 6 and 27. One patient each died of transplant necrosis, acute heart failure, and acute peritonitis. The remaining 2 patients died of aspiration pneumonia. Twentyfive postoperative complications developed. There were 17 anastomotic leaks, 14 of them in the neck healed with drainage for 1 to 2 weeks; the other 3 in the abdomen were corrected surgically through a laparotomy. Anastomotic stenosis occurred in 6 patients. Four of them were repaired with platysma myocutaneous flaps. Dilations and a plasty for the stricture were performed in 1 patient each. The postoperative abdominal incision dehiscence in 2 patients was oversewn successfully.

\section{Gastric Transposition}

Esophagectomy and gastric transpositions were performed by either a left thoracotomy ( 22 patients) or a right thoracotomy ( 3 patients) in 25 patients, including 2 with unsuccessful stents. An esophagogastrostomy was made in the thorax in 23 patients and in the neck in 2 patients. There were no deaths in these patients, but postoperative complications occurred in 3 patients. One of 2 patients with anas- tomotic stenosis was treated successfully with dilation, and the other was managed with platysma myocutanous flap repair. The remaining patient who had localized empyema postoperatively underwent local thoracoplasty 5 months later. Among the 23 patients undergoing intrathoracic esophagogastrostomy, 1 patient experienced mild regurgitation without requiring any treatment. Esophageal manometric examination in 3 patients showed that intraesophageal, anastomotic, and intragastric mean pressures were $-0.23 \mathrm{~mm} \mathrm{Hg}, 11.2 \mathrm{~mm} \mathrm{Hg}$, and $2.4 \mathrm{~mm} \mathrm{Hg}$, respectively.

\section{Platysma Myocutaneous Flap Repair}

The severe cervical esophageal or anastomotic stricture resistant to dilation was repaired with platysma myocutaneous flaps in 17 patients. Of them, cervical esophageal stricture caused by a caustic agent occurred in 4 patients, and anastomotic strictures after esophageal replacement developed in the remaining 13 patients. In the latter group 8 patients were transferred to our institute after undergoing colon interpositions at other hospitals. There were no major complications, but 1 patient had an anastomotic leak that was managed with drainage for 1 week. All the patients can eat soft or solid food postoperatively.

\section{Miscellaneous Procedures}

Of the 12 patients who underwent miscellaneous operations, 1 died of acute ileus 8 months after the surgical intervention. The major treatment modalities are summarized in Figure 3.

\section{Discussion}

Esophageal intraluminal stenting has been used to decrease the likelihood of stricture formation in patients with corrosive esophageal burns for several decades. ${ }^{12,}{ }^{13}$ Fell and 
colleagues ${ }^{14}$ had established the experimental foundation for the stenting treatment of caustic esophageal burns. Reyes and Hill ${ }^{11}$ tried this technique in cats with considerable success. Other authors ${ }^{15,16}$ reported success in the prevention and treatment of patients with severe corrosive esophageal burns using this method. Recently, Broto and associates ${ }^{17}$ presented their experience in treating cases of severe esophageal stenosis resistant to conventional dilatation through the placement of silicone stents. However, early work fell into disfavor because it was found that the strictures soon reformed after the stent was removed. This was because the timing of stent removal was too early. It is widely known that it takes several months for esophageal scars to be stabilized. We used modified intraluminal stenting to treat serious cases when such patients were admitted within 3 weeks after ingestion of a caustic agent. The esophageal stent was inserted 2 to 3 weeks after caustic agent ingestion. Of the 28 patients with esophageal stenting, 23 ate a normal diet after removal of a stent that had been kept in place for 4 to 6 months. One of the 23 patients had a thoracic esophageal perforation in the right side of the chest and was in crisis at the time of hospital admission. Salvage operations, including tube thoracotomy, jejunostomy, and esophageal stenting, were performed in the patient immediately. The abdominal esophagus was ligated with an absorbable thread to reduce the thoracic cavity pollution caused by gastric content regurgitation. In the wake of withdrawal of the stent 6 months after surgical intervention, barium swallow showed smooth passage of the contrast medium without stricture or perforation. Esophageal stenting has the advantages of an inexpensive device, readily available components in construction, being an easily performed procedure, and tolerable intervention, even by the depressed or mentally ill patient. ${ }^{12}$ Besides that, our procedure offers the following advantages: (1) maintaining nutrition through both the oral cavity and a gastrostomy; (2) reducing nose strain because the stent was fastened at both the nostril and the abdominal wall to prevent migration, allowing the patient to tolerate it for several months; (3) adjusting the displaced stent readily; (4) decreasing thoracic pollution in patients with a perforated esophagus; and (5) removing the stent conveniently.

Patients with severe and extensive esophageal strictures resistant to dilatations require esophageal reconstruction. It remains a controversy whether the burned esophagus would be resected or not during esophageal reconstruction. Kim and coworkers ${ }^{8}$ found that 7 patients had cicatricial carcinoma among the 54 patients with corrosive esophageal burns. The interval between injury and the development of cancer ranged from 29 to 46 years. Csikos and associates ${ }^{18}$ also reported 36 patients with scar cancer after swallowing corrosive agents. In their series the interval between the caustic burn and the diagnosis of scar carcinoma was 46.1 years. Therefore, they have suggested that esophagectomy, instead of bypass, should be performed in all the patients with corrosive esophageal severe strictures. However, on the basis of our experience, only the patients with strictures caudal to the carina have indications for esophagectomy. This is because there is a distance between the burned esophagus and its contiguous mediastinal organs. Performing esophagectomy is easier, and morbidity and mortality occurs less in these patients. As for the substitute organ for the esophagus, although colon or jejunum interposition can be performed, they are fraught with major complications and conduit loss. ${ }^{19}$ Some investigators ${ }^{15,16}$ have advocated using the stomach to reconstruct the esophagus because of its adequate length, dependable blood supply, the richness in the submucosal vascular network, its nature as a clean substitute for the esophagus, and the fact that relocation of the stomach requires only one anastomosis. In addition, gastric transposition was performed in most patients, and the thoracic surgeon can perform this procedure skillfully at our institute. Therefore, all 25 patients underwent esophagectomy and gastric transposition in this study. The mean operative time was 4 hours, and 200 to $900 \mathrm{~mL}$ (mean, 400 $\mathrm{mL}$ ) of blood was transfused intraoperatively in 23 of them. All but 2 patients underwent intrathoracic anastomosis. There was a high-pressure zone at the anastomotic site, but 24-hour pH study showed that DeMeester scores were 54.1 and 14.5 in 2 of these patients, respectively (normal range, $<14.72$ ). In another study at our institute, the DeMeester score was $89.2 \pm 109$ in 12 patients with intrathoracic anastomosis, and only 3 of them were in the normal range. That means the patients without symptoms might still have reflux. These patients are managed with lifestyle modification, such as elevating the head of the bed on 4- to 6-inch blocks and avoiding recumbency for 3 hours after meals. For patients with persistent reflux symptoms, $\mathrm{H}_{2}$-receptor blocking agents can be prescribed.

When a severe and extensive stricture is located proximal to the carina, colon interposition is indicated. Raffensperger and coworkers ${ }^{20}$ reported that 30 children with caustic strictures underwent colon interposition, and none had cicatricial cancer during the follow-up period. Helardot ${ }^{5}$ also claimed that if conditions of safe intensive care are not fulfilled, the esophagus is left in place and bypassed with a retrosternal gastric tube. In our series the operative time was 8 hours and 9 hours, respectively, and 1800 and $1900 \mathrm{~mL}$ of blood was transfused intraoperatively, respectively, in the 2 patients in whom the strictures were located at the upper third esophagus because the injured esophagus adhered to the neighboring mediastinal organs extensively and densely. Esophageal resection in these patients might predispose to massive bleeding and trauma to its contiguous vital organs. This is because strong alkali liquefies the tissue in most of the cases. Despite the stom- 
ach, jejunum, and colon being able to be used to replace the esophagus in these cases, the colon is a preferable conduit for esophageal replacement in light of its anatomic and physiologic features, including constant blood supply vessels, status as a long enough transplant to be pulled to the neck (even the hypopharynx), low incidence of disease itself, and resistance to gastric juice. We used the colon for an esophageal substitute in most of our patients in whom the stricture was located proximal to the carina. Among the 71 grafts, the vast majority (97.2\%) are of the left colon supplied by the middle colic artery. This is because of (1) the more constant and reliable arterial supply and venous drainage of the left colon, (2) the close match in the diameter of the left colon and esophagus, and (3) the author's preference. Thirty-seven colon interpositions had been performed before 1995, and 4 patients died postoperatively. The major complications were proximal anastomotic leak, which occurred in 10 patients, followed by anastomotic stenosis, which occurred in 5 patients. After 1995, 34 esophageal replacements with the colon were performed. Among them, 1 patient died, and postoperative complications included anastomotic leak in 4 patients and stricture in 1 patient. The mortality and morbidity decreased significantly. The following steps have been taken to reduce the postoperative complications: (1) creating a feeding gastrostomy or jejunostomy to maintain the nutrition; (2) avoiding tension or twisting of the graft and providing adequate blood supply; (3) performing a proximal anastomosis with a single-layer suture; and (4) adequately draining the site of the anastomosis.

The undilatable cervical esophageal or anastomotic stricture requires surgical intervention. Free jejunum and myocutaneous flap can be used to repair the serious stricture. Using jejunum to treat the esophageal stricture in the neck requires microvascular anastomosis, which is technically demanding. ${ }^{21}$ Myocutaneous flaps include pectoralis major and platysma. The drawback of the island pectoralis major myocutaneous flap is that it is bulky. ${ }^{22}$ The platysma myocutaneous flap is thin and broad and rich in blood supply. Friedman and associates ${ }^{23}$ reported that the inferiorly based platysma myocutaneous flap was used to reconstruct hypopharyngeal strictures in 2 patients with lye burns. Both of them were able to eat normally and had no significant stenosis. We successfully used the platysma flaps to repair 17 cervical esophageal or anastomotic strictures. When a patient has such a severe cervical stricture that it is impossible to judge the aboral extension of the stricture by endoscopy, computed tomographic scanning, or contrast study, either platysma myocutaneous flap repair or colon interposition is performed, depending on the intraoperative findings. The stricture is explored with a sternocleidomastoid approach first. If the distal end of the stricture is located proximal to the thoracic outlet, a flap repair is indicated.
Otherwise, if it extends into the chest, a colon interposition is selected. However, barium swallow in the 4 patients with severe cervical stricture caused by caustic agents and another 13 patients with proximal anastomotic stenoses confirmed that the aboral end of the stricture is above the thoracic outlet in our series. All the patients can swallow a normal diet without dysphagia postoperatively. The platysma myocutaneous flap offers the advantages of being thin, having an extensively available scope, being a simple procedure, causing mild trauma, and having a high survival rate. Consequently, we claim that the platysma myocutaneous flap is a suitable method for the repair of the undilatable cervical esophageal or anastomotic stricture.

\section{References}

1. Ramasamy K, Gumaste VV. Corrosive ingestion in adults. J Clin Gastroenterol. 2003;37:119-24.

2. Golfman LP, Weigert JM. Corrosive substance ingestion: a review. Am J Gastroenterol. 1984;79:85-90.

3. Wain JC, Wright CD, Kuo EY, Wilkins EW Jr, Grillo HC, Mathisen DJ. Long-segment colon interposition for acquired esophageal disease. Ann Thorac Surg. 1999;67:313-7.

4. Thomas P, Fuentes P, Giudicelli R, Reboud E. Colon interposition for esophageal replacement: current indications and long-term function. Ann Thorac Surg. 1997;64:757-64.

5. Helardot P. Caustic burns of the esophagus, esophagectomy and replacement with gastric tube: comparative study with other procedures. Saudi Med J. 2003;24(suppl):S39.

6. Chen HC, Chana JS, Chang CH, Feng GM, Ho-Asjoe M, Tang YB. A new method of subcutaneous placement of free jejunal flaps to reconstruct a diversionary conduit for swallowing in complicated pharyngoesophageal injury. Plast Reconstr Surg. 2003;112:1528-33.

7. Chen HC, Kuo YR, Hwang TL, Chen HH, Chang CH, Tang YB. Microvascular prefabricated free skin flaps for esophageal reconstruction in difficult patients. Ann Thorac Surg. 1999;67:911-6.

8. Kim YT, Sung SW, Kim JH. Is it necessary to resect the diseased esophagus in performing reconstruction for corrosive esophageal stricture? Eur J Cardiothorac Surg. 2001;20:1-6.

9. Kotsis L, Krisar Z, Orban K, Csekeo A. Late complications of coloesophagoplasty and long-term features of adaptation. Eur J Cardiothorac Surg. 2002;21:79-83.

10. Wang RW, Jiang YG, Fan SZ, Chen JM, Wu X, Zhao YP. Repair of stricture of cervical esophagus with platysma myocutaneous flaps. Chin Med J (Engl). 1999;112:132-5.

11. Reyes HM, Hill JL. Experimental treatment of corrosive esophageal burns. J Pediatr Surg. 1974;9:317-27.

12. Mills LJ, Estrera AS, Plat MR. Avoidance of esophageal stricture following caustic burns by the use of an intraluminal stent. Ann Thorac Surg. 1979;28:60-5.

13. Estra A, Taylor W, Mills LJ, Platt MR. Corrosive burns of the esophagus and stomach: a recommendation for an aggressive surgical approach. Ann Thorac Surg. 1986;41:276-83.

14. Fell SC, Denize A, Becker EH. The effect of intraluminal splinting on the prevention of caustic stricture of the esophagus. J Thorac Cardiovasc Surg. 1966;52:675-81.

15. de Jong AL, Macdonald R, Ein S, Forte V, Turner A. Corrosive esophagitis in children: a 30-year review. Int J Pediatr Otorhinolaryngol. 2001;57:203-11.

16. Ein SH. Gastric tubes in children with caustic esophageal injury: a 32-year review. J Pediatr Surg. 1998;33:1363-5.

17. Broto J, Asensio M, Vernet JM. Results of a new technique in the treatment of severe esophageal stenosis in children: poliflex stents. J Pediatr Gastroenterol Nutr. 2003;37:203-6.

18. Csikos M, Horvath O, Petri A, Petri I, Imre J. Late malignant transformation of chronic corrosive oesophageal strictures. Langenbecks Arch Chir. 1985;365:231-8. 
19. Hirschl RB, Yardeni D, Oldham K, Sherman N, Siplovich L, Gross E, et al. Gastric transposition for esophageal replacement in children: experience with 41 consecutive cases with special emphasis on esophageal atresia. Ann Surg. 2002;236:531-9; discussion 539-41.

20. Raffensperger JG, Luck SR, Reynolds M, Schwartz D. Intestinal bypass of the esophagus. J Pediatr Surg. 1996;31:38-46.

21. Chana JS, Chen HC, Sharma R, Gedebou TM, Feng GM. Microsurgical reconstruction of the esophagus using supercharged pedicled jejunum flaps: special indications and pitfalls. Plast Reconstr Surg. 2002;110:742-8.

22. Ananthakrishnan N, Nachiappan M, Subba Rao KS. Island pectoralis major myocutaneous flap for pharyngo-oesophageal strictures prior to oesphagocoloplasty. J R Coll Surg Edinb. 2001;46:202-4.

23. Friedman M, Schild JA, Venkatesan TK. Platysma myocutaneous flap for repair of hypopharyngeal strictures. Ann Otol Rhinol Laryngol. 1990;99:945-50.

\section{ON THE MOVE?}

Don't miss a single issue of the journal! To ensure prompt service when you change your address, please photocopy and complete the form below.

Please send your change of address notification at least six weeks before your move to ensure continued service. We regret we cannot guarantee replacement of issues missed due to late notification.

\section{JOURNAL TITLE:}

Fill in the title of the journal here.

\section{OLD ADDRESS:}

Affix the address label from a recent issue of the journal here.

NEW ADDRESS:

Clearly print your new address here.

Name

Address

City/State/ZIP
COPY AND MAIL THIS FORM TO:

Elsevier Inc.

Subscription Customer Service

6277 Sea Harbor Dr

Orlando, FL 32887
OR FAX TO:

407-363-9661

OR E-mail:

elspcs@elsevier.com
OR PHONE: 800-654-2452

Outside the U.S., call

407-345-4000 


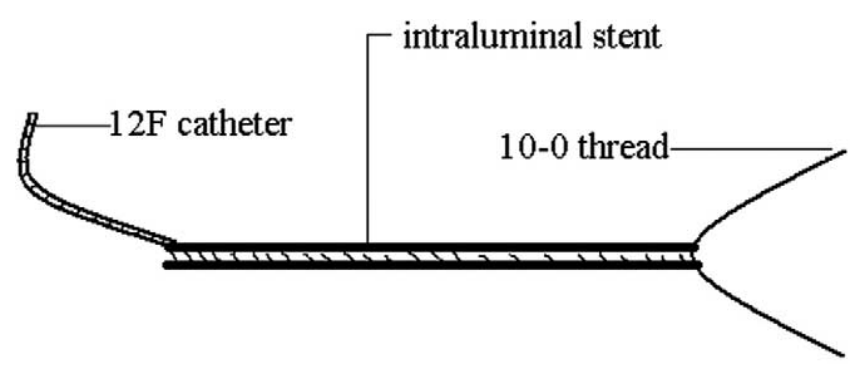

Figure E1. Detail of construction of the modified intraluminal stent. A $12 \mathrm{~F}$ catheter is affixed to the proximal end and the distal end is transfixed with 10-0 thread.

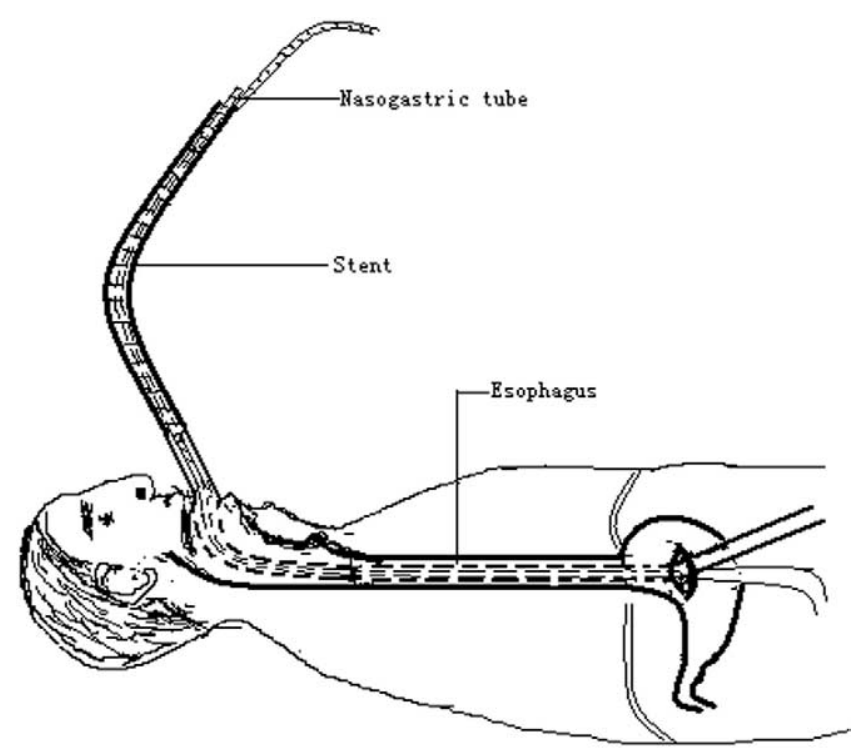

Figure E2. Insertion of stent in an antegrade fashion by pulling the 2 strings of 10-0 filament of which are connected with the distal end each of the stent and the sheathed nasogastric tube. 


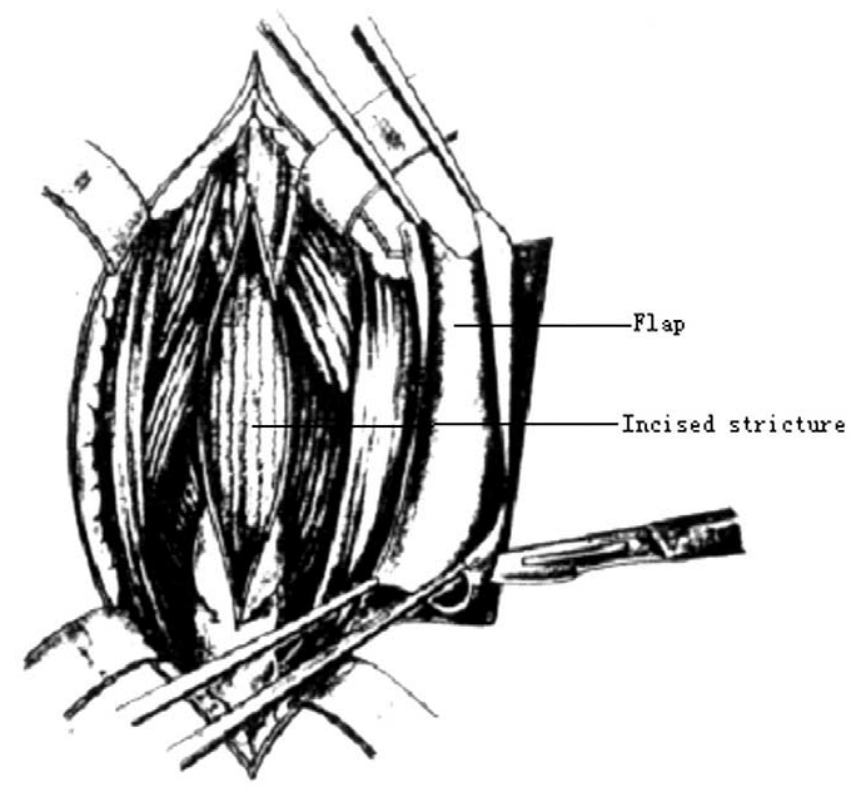

Figure E3. Mobilization of the platysma myocutaneous flap. Anterior, superior, and inferior sides are extended through the platysma, but the posterior side through the skin only down to the muscle.

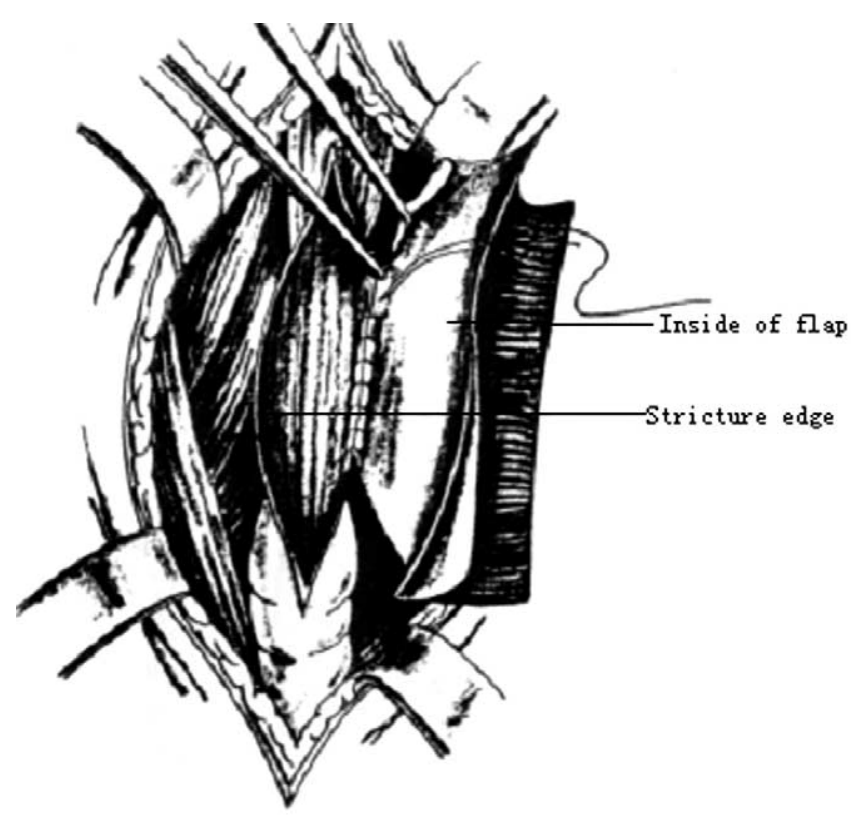

Figure E4. Suture of platysma myocutaneous flap to the incised esophageal stricture margin. 